\title{
Characterization of doxorubicin nanoparticles prepared by ionic gelation
}

\author{
Arwa Khalid ${ }^{1}$, Sajid Bashir ${ }^{1}$, Muhammad Sohail ${ }^{2}$, Muhammad Imran Amirzada ${ }^{2 \star}$ \\ ${ }^{1}$ Faculty of Pharmacy, University of Sargodha, Sargodha, ${ }^{2}$ Department of Pharmacy, COMSATS University Islamabad, \\ Abbottabad Campus, Abbottabad, Pakistan
}

*For correspondence: Email: imranamirzada@ciit.net.pk

\begin{abstract}
Purpose: To prepare and characterise doxorubicin nanopatrticles and study their drug delivery in breast cancer.

Methods: Doxorubicin nanoparticles were prepared by ionic gelation method using sodium alginate as polymer. The formulations were optimized by cross-linking $\mathrm{CaCl}_{2}$ with sodium alginate at different concentrations. Zeta sizer Nano ZS (UK) was used to determine the mean particle size distribution of the nanoparticle preparations. The shape and external morphologies of the nanoparticles were evaluated by scanning electron microscopy (SEM). Drug release was determined and kinetic release analysis was applied to determine the mechanism of drug release.

Results: Entrapment efficiency and mean particle size values were correlated. Scanning electron micrographs showed that the nanoparticles were spherical with little irregularity but without cracks. Doxorubicin release from the sodium alginate nanoparticles followed Korsmeyer-Peppas model which suggest that drug release from the nanoparticles was by diffusion and dissociation from the natural polymer matrix.

Conclusion: The doxorubicin-loaded nanoparticles showed concentration-dependent increases in entrapment efficiency. The nanoparticles displayed anticancer properties in breast cancer cell line, thus indicating its potential fo chemotherapeutic application.
\end{abstract}

Keywords: Doxorubicin, Ionic gelation, Nanoparticles, Sodium alginate, Drug release mechanism, Anticancer

This is an Open Access article that uses a funding model which does not charge readers or their institutions for access and distributed under the terms of the Creative Commons Attribution License (http://creativecommons.org/licenses/by/4.0) and the Budapest Open Access Initiative (http://www.budapestopenaccessinitiative.org/read), which permit unrestricted use, distribution, and reproduction in any medium, provided the original work is properly credited.

Tropical Journal of Pharmaceutical Research is indexed by Science Citation Index (SciSearch), Scopus, International Pharmaceutical Abstract, Chemical Abstracts, Embase, Index Copernicus, EBSCO, African Index Medicus, JournalSeek, Journal Citation Reports/Science Edition, Directory of Open Access Journals (DOAJ), African Journal Online, Bioline International, Open-J-Gate and Pharmacy Abstracts

\section{INTRODUCTION}

Doxorubicin (adriamycin) is an aromatic, heterocyclic, anthracycline antibiotic from the fungus Streptomyces peucetius [1]. Doxorubicin has wide spectrum of activity against all types of cancer [2]. It inhibits cell division and induces apoptosis. Doxorubicin forms a complex with
DNA and inhibits cell division, leading to inhibition of topoisomerase II in DNA transcription. It blocks the resealing of DNA double helix, thereby stopping the process of replication. The unwanted side effects of doxorubicin as well as various barriers to the effective administration of drugs can be ameliorated through targeted delivery to the site of tumor, and enhanced local concentration of 
the drug at the receptor site [3]. For drug delivery systems, a variety of biodegradable polymers are applied which show desirable, sustained, controlled, and targeted effect by keeping drug concentration within the therapeutic range.

Sodium alginate is a widely used polymer due to its biodegradable, biocompatible and mucoadhesive nature [4]. It is a sodium salt of alginic acid from marine brown algae. It contains two uronic acids, $\alpha$-L-guluronic and $\beta$-D-mannuronic acids. Guluronic acids exchange $\mathrm{Na}+$ ion and react with $\mathrm{Ca}^{2+}$ and $\alpha$-L-guluronic acid groups thus connecting each other by divalent cations. Dimerization of alginate chains help them to join with many other chains, resulting in formation of a gel network. Sodium alginate is widely used due to its ionotropic gelatin properties and crosslinked structure [5].

The aim of this work was to design a formulation for doxorubicin nanoparticles that will improve drug delivery and minimize doxorubicin resistance in breast cancer.

\section{EXPERIMENTAL}

\section{Materials}

Doxorubicin hydrochloride (RPG Life Sciences Limited, India), Chitosan , Sodium tripolyphosphate , Glacial acetic acid , Sodium hydroxide , Monobasic potassium phosphate , Calcium Chloride (Merk).

\section{Preparation of doxorubicin nanoparticles}

Nephelometry (DRT 100B turbidimeter, HF Instruments) was used to determine the concentration-dependence of interaction between alginate and calcium from pre-gel, precipitation and aggregation regions due to the linkage between calcium and alginate ions. Calcium chloride $(0.3 \% \mathrm{w} / \mathrm{v})$ was added dropwise, in $10 \mathrm{ml}$ to $1.0 \mathrm{ml}$ increments depending on changes in turbidity, to $20 \mathrm{ml}(0.1 \% \mathrm{w} / \mathrm{v})$ sodium alginate solution. The nephelometer cell was constantly stirred after each addition of calcium chloride, and the solution and the system were equilibrated for $5-7 \mathrm{~min}$ before recording the turbidity (NTU) for solution $\mathrm{pH}$ [4]. Sodium alginate and calcium chloride at different ratios were used for preparation of formulations designated as DOX-4, DOX-5, DOX-6 DOX-7, and DOX-8 (Table1). Each doxorubicin nanoparticle formulation was prepared in triplicate viz DOX-4 (a, b, c), DOX-5 (a, b, c), DOX-6 (a, b, c), DOX-7 (a, b, c), and DOX-8 (a, $b, c)$. Solutions of sodium alginate at different concentrations $(0.4-1 \mathrm{mg} / \mathrm{ml})$ were prepared by dissolving weighed quantities of the salt in distilled water at $37^{\circ} \mathrm{C}$ and stirring at $700 \mathrm{rpm}$ for $25 \mathrm{~min}$. The drug was added to pre-solubilized alginate solution and stirred for 20 min until it was completely mixed. Calcium chloride $\left(\mathrm{CaCl}_{2}\right)$ solutions (18 mM and $36 \mathrm{mM}$ ) were prepared by dissolving $199.8 \mathrm{mg}$ and $399.6 \mathrm{mg}$, respectively in $100 \mathrm{ml}$ of deionized water. The $\mathrm{CaCl}_{2}$ solution was injected drop-wise into the sodium alginate solution and stirred for $1 \mathrm{~h}$ at $1500 \mathrm{rpm}$. The resultant nanoparticles were purified using ultracentrifugation.

A series of ratios of calcium chloride-to-sodium alginate were used to formulate chitosanalginate nanospheres. The purpose of the aqueous calcium chloride addition was to identify a series of calcium chloride-to-sodium alginate mass ratios that formed nanoparticles with low mean particle size, polydispersity, and maximum particle concentration.

\section{Preparation of doxorubicin conjugates}

Sodium alginate and Calcium chloride with different ratios were used for formulations, named as DOX-4, DOX-5 and DOX-6 DOX-7, DOX-8 (Table1). Solutions of sodium alginate with different concentrations of $0.4-1 \mathrm{mg} / \mathrm{ml}$ were prepared by dissolving weighed quantities of Sodium alginate in distilled water at $37^{\circ} \mathrm{C} / 700$ rpm for 25 minutes. Drug was added into presolublized alginate solution and stirred for 20 minutes until drug was completely mixed.

Table 1: Composition of doxorubicin nanoparticles

\begin{tabular}{lccc}
\hline Formulation & $\begin{array}{c}\text { Drug } \\
(\mathbf{m g} / \mathbf{m l})\end{array}$ & $\begin{array}{c}\text { Alginate } \\
(\mathbf{m g} / \mathbf{m l})\end{array}$ & $\begin{array}{c}\mathbf{C a C l}_{\mathbf{2}} \\
(\mathbf{m M})\end{array}$ \\
\hline DOX-4 & 0.1 & 0.4 & 36 \\
DOX-5 & 0.1 & 0.5 & 36 \\
DOX-6 & 0.1 & 0.6 & 36 \\
DOX-7 & 0.1 & 0.8 & 18 \\
DOX-8 & 0.1 & 1 & 18 \\
\hline
\end{tabular}

Calcium chloride $\left(\mathrm{CaCl}_{2}\right)$ solutions of $18 \mathrm{mM}$ and $36 \mathrm{mM}$ were prepared by dissolving 199.8 and $399.6 \mathrm{mg}$, respectively, in $100 \mathrm{ml}$ deionized water. The solution was injected dropwise into sodium alginate solution and agitated for $1 \mathrm{~h}$ at $1500 \mathrm{rpm}$. The nanoparticles were separated by ultracentrifugation.

\section{Evaluation of effect of calcium chloride to sodium alginate mass ratio on particle size of nanoparticles}

A series of calcium chloride to sodium alginate ratios were used to formulate chitosan-alginate nanospheres. The purpose of this aqueous calcium chloride addition was to identify a series of calcium chloride to sodium alginate mass 
ratios that formed nanoparticles with a low mean particle size, polydispersity, and maximum particle concentration. sodium alginate mass kept constant to evaluate the mass ratio of calcium chloride to sodium alginate which varied to prepare chitosan-alginate nanospheres [4]

\section{Determination of particle size by zeta sizer}

The mean particle size was measured with photon correlation spectroscopy (PCS) at a fixed angle of 90 (Zetasizer $3000 \mathrm{HS}$, Malvern Instrument, UK). Nano dispersion was appropriately diluted to measure mean particle size and polydispersity index [6].

Doxorubicin $(10 \mathrm{mg}$ ) was added to $25 \mathrm{ml}$ of phosphate buffered saline (PBS, pH 7.4) in a volumetric flask and the resultant solution was stirred with a magnetic stirrer for maximum dissolution of the drug. Then, the volume of the solution was made up to $100 \mathrm{ml}$ with PBS to give a doxorubicin concentration of $0.01 \mathrm{mg} / \mathrm{ml}$.

\section{Assessment of shape and surface morphology}

Shape and external morphology of nanoparticles were evaluated by using scanning electron microscope (SEM). SEM samples were arranged by smattering nanoparticles onto an aluminum stub with the help of double adhesive tape. The nanoparticles shape and surface morphology was were examined under scanning electron microscope (SEM) (JEOL, JSM-6100 SEM, JAPAN) $[14,15]$.

\section{Determination of entrapment efficiency}

Separation of nanoparticles determined the amount of encapsulated doxorubicin. Separation was carried out by ultra-centrifugation of formulations at $15000 \mathrm{rpm}$, Temp $4 \stackrel{\circ}{\circ} \mathrm{C}$ for $1 \mathrm{~h}$. The nanoparticles were separated from the supernatant, and sonicated for $15 \mathrm{~min}$ to obtain a uniform solution. The quantity of entrapped doxorubicin was determined spectrophotometrically at a wavelength of 483 $\mathrm{nm}$. Entrapment efficiency (EE) of doxorubicin was calculated as in Eq 1 [11].

$E E=\{(T-S) / T\} 100$

where $T$ is the total drug present in the nanoparticles and $S$ is the amount of free drug present in the supernatant.

\section{In-vitro drug release studies}

In vitro release of doxorubicin from its nanoparticles was determined with Dialysis method. Phosphate buffered saline $(\mathrm{pH} 7.4)$ was used as a release medium. Entrapped drug 100 $\mathrm{ml}$ centrifuged, supernatant was discarded and remaining portion suspended into $5 \mathrm{ml}$ of buffer. Dialysis bag was washed with distilled water and the suspended formulation added, placed into $100 \mathrm{ml}$ of buffer. Temperature was kept constant to $37 \pm 1{ }^{\circ} \mathrm{C}$ and the stirring speed was $100 \mathrm{rpm}$ for the release medium. After every one-hour 5 $\mathrm{ml}$ of the sample was taken and equal quantity of fresh buffer was added. Results were concluded from mean value of three runs [8].

\section{Calibration studies on oxorubicin in phosphate buffered saline (pH 7.4)}

Doxorubicin (10 mg) was added to $25 \mathrm{ml}$ of phosphate buffered saline (PBS, $\mathrm{pH} 7.4$ ) in a volumetric flask and this solution was stirred by magnetic stirrer for dissolving maximum quantity of drug. Then the volume of solution was made up to $100 \mathrm{ml}$ with same solvent. This gave a concentration of $0.01 \mathrm{mg} / \mathrm{ml}$. This solution was stock standard solution and further dilutions were done by this solution. After dilution each solution contained $0.05,0.025,0.0125,0.00625,0.0031$ $\mathrm{mg} / \mathrm{ml}$. Absorbance was taken at $483 \mathrm{~nm}$ and standard curve was drawn.

\section{Drug release kinetic analysis}

Drug release kinetic analysis regarding all formulations was applied in excels by using addin DDSolver software to find out the highest values of regression coefficient. To make a comparative studies on Zero order, First order, Highuchi, Hixon-Crowell, Korsmeyer-Peppas model and to check out the pattern of drug release [9].

\section{Application of Korsmeyer-Peppas model}

Korsmeyer-Peppas model equation derived a simple relationship which defined drug release from a polymeric system. It is ordinarily used model to understand the release performance of drug from hydrophilic matrix. Graph was plotted between log cumulative percentages of drug released versus log time as shown in Eq 2.

$\mathrm{Ktn}=\mathrm{Mt} / \mathrm{Ma}$

where $\mathrm{Mt} / \mathrm{Ma}$ is the amount of drug release at time t. $\mathrm{K}$ is a constant which include the properties of the macromolecular polymeric 
system and drug. While $\mathrm{n}$ is kinetic constant related to release mechanism of drug. If the value of $n \leq 0.43$ then the release pattern follows Fickian diffusion, on the other hand if the value of $n>0.43$ but $<0.89$ then release pattern is nonFickian transport, $\mathrm{n}=0.89$ for case II (relaxational or zero order) release and $n>0.89$ for super case II transport [10].

\section{Statistical analysis}

The data are expressed as mean \pm SD. The statistical analysis was carried out using SPSS 18. Comparison of formulations was by one-way analysis of variance (ANOVA). Values of $p<$ 0.05 considered statistically significant.

\section{RESULTS}

\section{Particle size}

Doxorubicin-loaded alginate nanoparticles were in the size range of $6638-3997 \mathrm{~nm}$, and mean particle size of $320-490.4 \mathrm{~nm}$. The particle size of drug-loaded nanoparticles was determined by Malvern zeta sizer (Table 2).

Table 2: Particle size and polydispersity of formulations

\begin{tabular}{lcc}
\hline Formulation & $\begin{array}{c}\text { Z-average ( } \\
\mathbf{n m})\end{array}$ & $\begin{array}{c}\text { Polydispersity } \\
\text { index }\end{array}$ \\
\hline DOX-4 & 350 & 0.481 \\
DOX-5 & 479 & 0.139 \\
DOX-6 & 490 & 0.273 \\
DOX-7 & 3997 & 1 \\
DOX-8 & 6638 & 1 \\
\hline
\end{tabular}

\section{Shape and surface morphology}

Shape and surface morphology of nanoparticles were evaluated by scanning electron microscope (SEM) to evaluate drug entrapment. Nanoparticles obtained from mixture of alginate and $\mathrm{CaCl} 2$ were spherical in shape with some irregularity. Nanoparticles surface appearance was slightly porous and free from cracks (Figure 1).

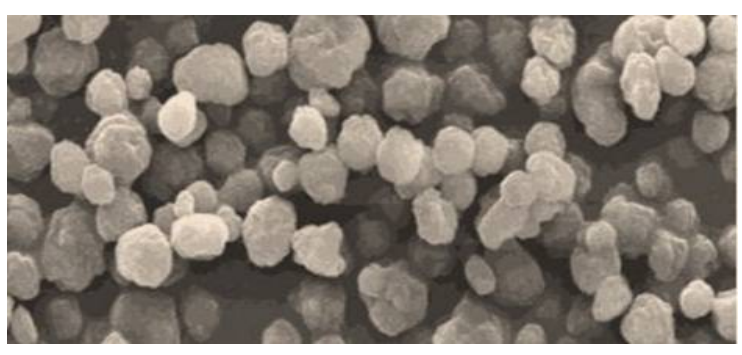

Figure 1: Scanning electron micrographs of drugloaded sodium alginate and $\mathrm{CaCl} 2$ nanoparticles

\section{Entrapment efficiency of doxorubicin nanoparticles}

The percentage entrapment efficiencies of the doxorubicin nanoparticles were in the range of 56.9 - $84 \%$ (Table 3).

Table 3: Entrapment efficiency of doxorubicin nanoparticles

\begin{tabular}{lccccc}
\hline \multirow{2}{*}{$\begin{array}{l}\text { Formulation } \\
\text { code }\end{array}$} & \multicolumn{2}{c}{ Absorbance (483nm) } & Mean & $\begin{array}{c}\text { EE } \\
\text { (\%) }\end{array}$ \\
\cline { 2 - 4 } & $\mathbf{a}$ & $\mathbf{b}$ & $\mathbf{C}$ & & \\
\hline DOX-4 & 0.590 & 0.587 & 0.589 & 0.589 & 65 \\
DOX-5 & 0.618 & 0.619 & 0.610 & 0.615 & 68 \\
DOX-6 & 0.640 & 0.641 & 0.650 & 0.643 & 71 \\
DOX-7 & 0.695 & 0.699 & 0.693 & 0.697 & 77 \\
DOX-8 & 0.759 & 0.761 & 0.7959 & 0.759 & 84 \\
\hline
\end{tabular}

Note: Doxorubicin nanoparticle formulations were prepared in triplicate and coded as DOX-4 (a,b,c), DOX-5 (a,b,c), DOX-6 (a,b,c), DOX-7 (a,b,c), DOX-8 $(\mathrm{a}, \mathrm{b}, \mathrm{c})$

Formulation DOX-8 showed the highest entrapment of $84 \%$. Entrapment efficiencies of the nanoparticle formulations of doxorubicin were determined by measuring their absorbance. Three absorbance values were taken consecutively and the mean absorbance values of DOX-4, DOX-5, DOX-6, DOX-7 and DOX-8 were $0.589,0.615,0.643,0.697$ and 0.759 , respectively. The absorbance varied directly with polymer concentration. The entrapment efficiency was also concentration-dependent i.e. it increased with increasing concentration of dispersing agent.

\section{In vitro drug release}

Maximum release of nanoparticles in phosphate buffer, $\mathrm{pH} 7.4$ was observed up to $32 \mathrm{~h}$. The drug release rate from the nanoparticles decrease with increase in polymer concentration. The dissolution profiles for formulations DOX-4 DOX-6 were evaluated, and a graph of drug release against time was plotted (Figure 2). Drug release for DOX-4 formulation was highest, but was gradually decreased for formulations DOX-5 and DOX-6. Drug release profile interpret the relationship of concentration of polymer and drug release property. Increase in polymer concentration decreased the release of drug from nanoparticles. The reverse was the case with respect to entrapment efficiencies of the nanoparticles. 


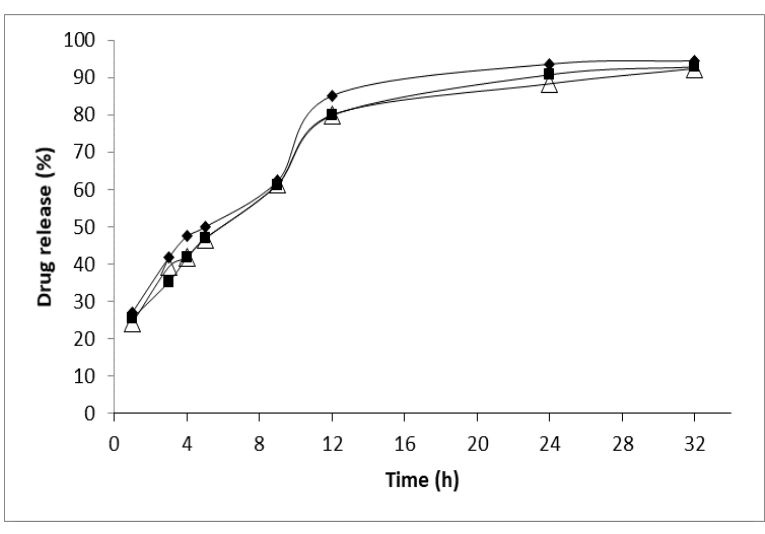

Figure 2: In-vitro drug release profile of nanoparticle formulations. = DOX-4; $\boldsymbol{\|}=\mathrm{DOX}-5 ; \Delta=\mathrm{DOX}-6$

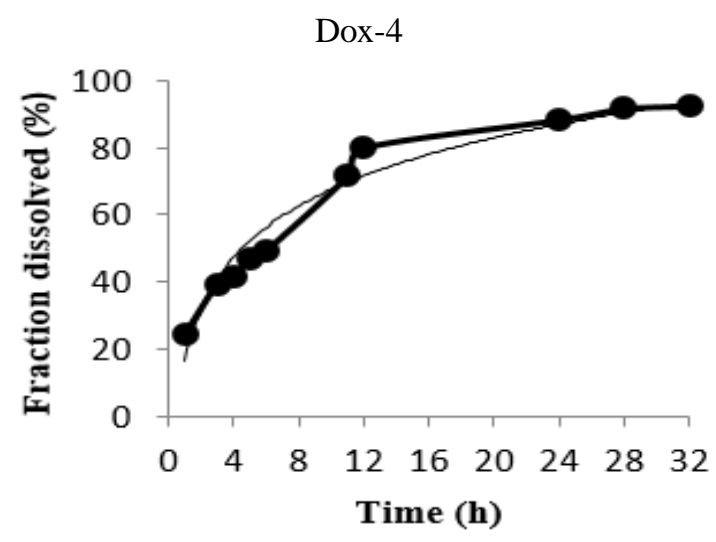

Dox-5

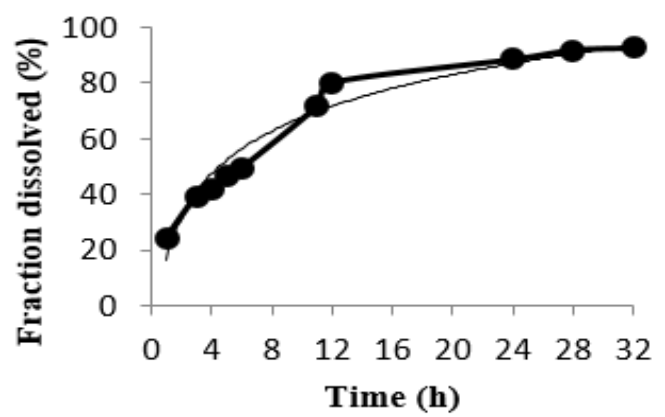

Dox-6

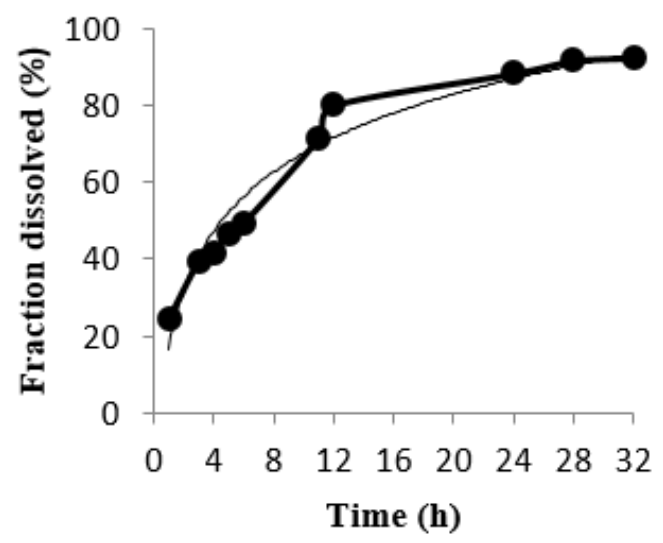

Figure 3: Korsmeyer-Peppas plots for doxorubicin nanoparticles
Table 5: Kinetic drug release data

\begin{tabular}{lcccl}
\hline Kinetic & & \multicolumn{3}{c}{ Formulation } \\
\cline { 3 - 5 } order/model & & $\mathbf{D O X}-\mathbf{4}$ & $\mathbf{D O X}-\mathbf{5}$ & $\mathbf{D O X}-\mathbf{6}$ \\
\hline Zero & $\mathrm{R}^{2}$ & 0.6680 & 0.4072 & 0.5051 \\
& $\mathrm{~K}_{\mathrm{o}}$ & 4.197 & 4.019 & 4.079 \\
First & $\mathrm{R}^{2}$ & 0.8984 & 0.9320 & 0.92 \\
& $\mathrm{~K}_{1}$ & 0.131 & 0.119 & 0.121 \\
Higuchi & $\mathrm{R}^{2}$ & 0.830 & 0.8934 & 0.8708 \\
& $\mathrm{~K}_{\mathrm{HC}}$ & 19.81 & 19.19 & 19.193 \\
Korsmeyer- & $\mathrm{R}^{2}$ & 0.939 & 0.9629 & 0.954 \\
Peppas & $\mathrm{K}_{\mathrm{P}}$ & 28.55 & 26.03 & 26.66 \\
& $\mathrm{n}$ & 0.364 & 0.368 & 0.377 \\
Hixon- & $\mathrm{R}^{2}$ & 0.852 & 0.885 & 0.870 \\
Crowell & & & & \\
\hline
\end{tabular}

Cumulative in-vitro drug release of formulations DOX-4 to DOX-6 were compared by plotting graph time vs. drug release as shown in Figure 3 . The results indicate the drug release pattern for all pre-designed formulations. These graphs shows the direct relationship of fraction of drug dissolved with passage of time. During time interval of $12-15 \mathrm{~h}$, drug profile show maximum absorbance and later variation in drug absorbance observed.

\section{Drug release kinetics}

Data collected from in vitro release studies of all formulations was fitted into the KorsmeyerPeppas model using DD Solver software. The results indicated that drug release followed the Korsmeyer-Peppas model pattern due to higher regression coefficient values in KorsmeyerPeppas model. The DOX-1 value of $\mathrm{n}$ was < 0.43 , while DOX-2 and DOX- 3 values of $n$ were 0.43 to 0.45 , respectively.

\section{DISCUSSION}

Doxorubicin-loaded albumin-loaded nanoparticles for targeting cancer cells have been prepared using coacervation method. Characterization of the nanoparticles formulation disclosed a sustained release effect. Polymeric nanoparticles can be prepared with a biodegradable hydrophilic polymer such as sodium alginate. Studies have shown that sodium alginate is extensively used in microparticle preparation due to its ionotropic gelation property and ability to react with cations [5].

In the current study, doxorubicin nanoparticles prepared using ionic gelation method showed some interesting advantages over previously prepared doxorubicin nanoparticles. The particles prepared in this study had a higher entrapment efficiency, and the entrapment efficiency increased with increase in polymer 
concentration. The DOX-4 - DOX-7 formulations had low entrapment efficiencies. This might be due to variation in $\mathrm{pH}$ or stirring speed during addition of cross linking solution to the polymer solution [12].

The release rate of doxorubicin depended on the concentration of the polymer. Drug release from the nanoparticles decreased with increase in polymer concentration. The polymer increased concentration build-up through cross-linking between the polymer and cross-linking agent. This retards the release of the entrapped drug. Particles were out of range with maximum polydispersity value at higher polymer concentration with low concentration of cross linker concentration. The particle size was decreased when alginate concentration was decreased along with increased calcium chloride concentration. The DOX-1 value indicated that the drug release followed Fickian diffusion pattern. Drug release from DOX-2 and DOX-3 followed the anomalous transport kinetics with a combination of two diffusion mechanisms and super case II transport. This was also previously revealed by Marcato et al [13].

\section{CONCLUSION}

Sustained release nanoparticles of doxorubicin have been successfully prepared by ionic gelation method. Entrapment efficiency is high in alginate nanoparticles, up to $71 \%$. The nanoparticles displayed anticancer properties in breast cancer cell line, thus indicating its potential for chemotherapeutic application.

\section{DECLARATIONS}

\section{Acknowledgement}

This research was supported by HEC (NRPU) Programme. The authors appreciate the Faculty and Research staff of Department of Pharmacy, University of Sargodha for their support.

\section{Conflict of Interest}

No conflict of interest associated with this work.

\section{Contribution of Authors}

The authors declare that this work was done by the authors named in this article and all liabilities pertaining to claims relating to the content of this article will be borne by them.

\section{REFERENCES}

1. Lown J. Anthracycline and anthraquinone anticancer agents: current status and recent developments. Pharmacol Ther 1993; 60(2): 185-214.

2. Yesair DW, Schwartzbach E, Shuck D. Comparative Pharmacokinetics of Daunomycin and Adriamycin in Several Animal Species Comparative Pharmacokinetics of Daunomycin and Adriamycin in Several Animal Species1. Cancer Res 1972; 32: 1177-1183.

3. Han $M$, Diao $Y Y$, Jiang $H L$, Ying $X Y$, Chen $D W$, Liang WQ, Gao JQ. . Molecular mechanism study of chemosensitization of doxorubicin-resistant human myelogenous leukemia cells induced by a composite polymer micelle. Int J Pharm 2011; 420(2): 404-411.

4. De $S$, Robinson $D$. Polymer relationships during preparation of chitosan-alginate and poly-l-lysinealginate nanospheres. J Control Release 2003; 89(1): 101-112.

5. Murano E. Use of natural polysaccharides in the microencapsulation techniques. J Appl Ichthyol 1998; 14(3-4): 245-249.

6. Subedi RK, Kang KW, Choi H-K. Preparation and characterization of solid lipid nanoparticles loaded with doxorubicin. Eur J Pharm Sci 2009; 37(3-4): 508-513.

7. Dave $R$, Patel R. Preparation and Characterization of Doxorubicin $\mathrm{HCl}$ Loaded Chitosan Nanoparticles by W/O Emulsion Method. Int J Pharm Life Sci 2013; 4(2): 2407-2413.

8. Zhang L, Granick S. How to stabilize phospholipid liposomes (Using nanoparticles). Nano Letters. 2006; 6(4): 694-698.

9. Barzegar-Jalali $M$, Adibkia $K$, Valizadeh $H$, Shadbad MRS, Nokhodchi A, Omidi $Y$, et al. Kinetic analysis of drug release from nanoparticles. J Pharm Pharm Sci 2008; 11(1): 167-177.

10. Brunner E. Velocity of reaction in non-homogeneous systems. Zeit Phys Chem 1904; 47: 56-102.

11. Mitra S, Gaur U, Ghosh PC, Maitra AN. Tumour targeted delivery of encapsulated dextran-doxorubicin conjugate using chitosan nanoparticles as carrier. $J$ Control Release 2001; 74(1-3): 317-323.

12. Marrache $S$ and Dhar $S$. Engineering of blended nanoparticle platform for delivery of mitochondria-acting therapeutics. PNAS 2012; 109(40): 16288-16293.

13. Marcato $P$, Leonardo FA, Raquel de MB, Patricia SM, lasmin RF, Larissa de $P$, Nelson D, and Amedea BS. Development of a Sustained-release System for Nitric Oxide Delivery using Alginate/Chitosan Nanoparticles. Curr Nanosci 2013; 9(1): 1-7. 